\title{
Muscle Weakness Upper Limb
}

National Cancer Institute

\section{Source}

National Cancer Institute. Muscle Weakness Upper Limb. NCI Thesaurus. Code C78459.

A reduction in the streng th of the upper limb muscles. 